\title{
EDWARD FUCHS: A HISTÓRIA DE ARTE NAS VELAS DO MATERIALISMO DIALÉCTICO
}

\author{
Maria João Cantinho
}

\begin{abstract}
RESUMO
O que mais fascinou Walter Benjamin, na análise da obra de Fuchs, ao ponto de the dedicar um ensaio intitulado "Eduard Fuchs, o colecionador e o historiador" foi essa zona de limiar ou de passagem, ocupada pelo historiador, que preconizava uma nova forma de operar sobre a investigação histórica, na sua época. Este apontava para uma mudança de paradigma da investigação histórica, aproximada àquela que Benjamin defendia, numa visão materialista dialéctica, ao arrepio das concepções progressistas da história. $O$ meu propósito é justamente assinalar os pontos de viragem deste modelo, relativamente aos anteriores e o modo como se aproximava este modelo da própria concepção benjaminiana da história e do saber alegórico.
\end{abstract}

Palavras-chave: História. Materialismo. Arte

\section{EDWARD FUCHS: THE HISTORY OF THE ART IN THE SAILING OF DIALECTIC MATERIALISM}

\begin{abstract}
What fascinated Walter Benjamin the most, in the analysis of Fuchs' work, up to the point of having dedicated an essay titled "Edward Fuchs, the collector and historian" was the area of passage, occupied by the historian, that preconized a new way of working on historical investigation, during his time. Fuchs hinted at a paradigm switch on historical investigation, close to what Benjamin also defended, through materialistic dialectics, in opposition to progressive conceptualizations of history. My goal is to mark the turning points of this model, in relation to the former model, and how close it is to a Benjaminian concepts of history and allegorical knowledge.
\end{abstract}

Key words: Histor. Materialis. Art

Professora do Instituto de Arte, Design e Empresa (IADE - Lisboa). Doutora pela Universidade Nova de Lisboa. Portuguesa, residente em Lisboa - Portugal. Email: micantinho@gmail.com 
"A recusa da ideia de um contínuo da história postulada no ensaio sobre Fuchs tem de ter consequências epistemológicas;

uma das mais importantes dessas consequências parece-me ser a determinação das fronteiras traçadas para o conceito do progresso na história."

Walter Benjamin.

Uma das reflexões fundamentais do pensamento de Walter Benjamin, oriundo da área de filosofia, foi justamente sobre a história e sobre o seu modo de produção. Tendo sido um autor que criticou, não apenas os instrumentos como a própria metodologia utilizada pela história, Walter Benjamin sentiu que a sua época anunciava uma nova forma de construção da história e de reprodução da obra de arte. Na verdade, e este é o pressuposto fundamental, não era possível continuar a olhar para a arte da mesma forma que os historiadores do seu tempo o faziam e ele ter-se-á confrontado com esta mesma questão com que nos ocupamos hoje: "O que fazem os historiadores quando estudam Arte?"

Se a técnica é uma manifestação histórica, resultando do avanço da evolução que foi determinada pelo capitalismo, então é necessário pensar o modo como essa manifestação histórica afectou a obra de arte e o seu conhecimento. Isto é, pensar na forma como a técnica se tornou matéria primeira, não só das ciências, como também da própria arte, no sentido em que veio contribuir para uma nova forma de produção artística, como também para uma nova forma de recepção dessas novas formas. Disso se ocupa Benjamin longamente, nos seus textos Pequena História da Fotografia e A Obra de Arte na Era da sua Reprodutibilidade Técnica.

Este contexto, o da emergência de um novo olhar sobre a arte, é precisamente aquele que contextualiza a obra de um historiador como Eduard Fuchs, pois, como o afirma o próprio Walter Benjamin, "O perfil histórico da obra de Fuchs destaca-se sobre este pano de fundo" (BENJAMIN, 2010, 119), por várias razões, sendo esse conjunto particular de razões que prende a atenção de Benjamin, aproveitando a sua pesquisa para ensaiar já uma série de pressupostos que desenvolverá na sua obra. É difícil dizê-lo com certeza, mas é provável que a natureza complexa do trabalho de Fuchs possa ter 
servido de inspiração e de irradiação para o próprio trabalho que Benjamin procurava levar a cabo.

No regresso de lbiza a Paris, em Outubro de 1933, Benjamin escreveu a Gretel Adorno, no início de Novembro, dando-Ihe conta de um encontro marcante: "Encontrei-me com Fuchs, um homem de uma admirável força vital" (BENJAMIN, 1998, 309). A partir dessa data, dado o interesse de Horkheimer, que the encomendou um artigo para a Revista de Investigação Social, Benjamin inicia a sua pesquisa sobre Eduard Fuchs. Provavelmente Benjamin ter-se-á encontrado com Fuchs mais de uma vez, entre esse mês de Outubro de 1933 e o mês de Maio de 1934, existindo, ainda, um registo de um encontro na Primavera de 1934 e a intenção de Benjamin redigir um ensaio sobre Fuchs deve ter-se tornado mais definida nessa altura, na medida em que, nesse Verão, Benjamin já mergulhara na leitura de Fuchs.

O que se sabe é que esse ensaio foi interrompido e adiado, pedindo Benjamin um alargamento do prazo para a redacção do artigo. A correspondência durante esse período, com Horkheimer, Scholem, Adorno e Gretel, dá-nos conta de todo o processo da redacção, das hesitações e adiamentos, reflectindo também a relação complexa e controversa de Benjamin com o Instituto de Investigação Social., bem como a situação desesperada em que se encontrava. É numa carta dirigida a Horkheimer, datada de 28 de Fevereiro de 1937 (GB V, 463) que Benjamin diz ter enviado nessa data o trabalho sobre Fuchs e, após as correcções de Horkheimer, o artigo é finalmente publicado.

$\mathrm{Na}$ mesma época já preparava aquela que viria a ser a sua obra publicada postumamente, Das Passagenwerk, em que se dedicava à reflexão sobre o paradigma epistemológico da História, mas também já tinha presente o que viria a ser o seu último texto, Sobre o conceito de história. Refiro-me aqui a estas obras de Walter Benjamin pela pertinência do tema, que o ocupava sobremaneira: a questão da história e a sua crítica ao conceito do Progresso. Partes do ensaio sobre Fuchs serão posteriormente integradas nas teses sobre a história, como o próprio Benjamin afirma, numa carta que dirige a Horkheimer, datada de 22 de Fevereiro de 1940:

Acabo de redigir algumas teses sobre o conceito da História. Estas teses ligam-se, por um lado, aos pontos de vista esboçados no Professora do Instituto de Arte, Design e Empresa (IADE - Lisboa). Doutora pela Universidade Nova de Lisboa. Portuguesa, residente em Lisboa - Portugal. Email: micantinho@gmail.com 
capítulo I do «Fuchs», e servirão, por outro lado, de armadura teórica para o segundo ensaio sobre Baudelaire (BENJAMIN, 1999, 400).

Quando Walter Benjamin decide redigir este ensaio, o seu objectivo é claro e articula-se com as preocupações que têm vindo a ocupar o seu pensamento durante a década de $3^{\circ} \mathrm{e}$, sobretudo a partir de 1936. A figura de Fuchs e o seu trabalho enquadram-se justamente naquilo que constitui, aos olhos de Walter Benjamin, o novo paradigma da compreensão e da leitura da história, tal como ele a defende, não só nas suas teses, em Sobre o Conceito de História, como também na sua obra O Livro das Passagens. Na verdade, o ensaio "Eduard Fuchs, colecionador e historiador" é o pontapé de saída de Benjamin para a abordagem da questão do materialismo dialéctico aplicado à história, naquele que foi um dos pontos fundamentais da sua ruptura com o paradigma vigente da história (vista sob a perspectiva do historicismo) e a sua defesa para uma nova forma de olhar e de ler a história.

Como podemos ler na sua obra O Livro das Passagens, "Ser dialéctico significa ter o vento da história nas velas. As velas são os conceitos. Porém, não é suficiente dispor de velas. Aquilo que é decisivo é a arte de as saber meter" (BENJAMIN, 1982, [N, 9, 8]). Dispor os conceitos, eis do que se trata, saber operar com eles, de modo a "revelar uma síntese autêntica" (BENJAMIN, 1992, [N 9a, 4]). A proposta benjaminiana, face à perspectiva da história do progresso contém esse esse propósito de abertura da história, no sentido em que procura salvar o objecto histórico arrancando-o à continuidade da história, isto é, a essa dimensão que anula o fenómeno histórico por dissolvê-lo nesse contínuo, onde os acontecimentos da história desaparecem sob a aparência do mesmo e da repetição. E o momento crítico da visão do materialismo histórico é precisamente o da "desintegração da continuidade histórica" (BENJAMIN, 1982, [N 10 a, 1]), aquela que permite ao objecto histórico constituir-se. Também na sua obra Sobre o Conceito de História, Benjamin definia como tarefa do materialista histórico o "escovar a contrapelo" a ideia convencional da história da cultura:

Não há documento de cultura que não seja também documento de barbárie. $\mathrm{E}$, do mesmo modo que ele não pode libertar-se da barbárie, assim também o não pode o processo histórico em que ele transitou de um para outro. Por isso o materialista histórico se afasta quanto pode desse processo de transmissão da tradição, atribuindose a missão de escovar a história a contrapelo. (BENJAMIN, 2010, 12-13).

Professora do Instituto de Arte, Design e Empresa (IADE - Lisboa). Doutora pela Universidade Nova de Lisboa. Portuguesa, residente em Lisboa - Portugal. Email: micantinho@gmail.com 
Se o conceito de cultura, como diz Benjamin, "é problemático para o materialismo histórico, a sua degeneração e transformação em mercadorias que se tornaram objectos de posse para a humanidade, é para ele, uma ideia inconcebível" (BENJAMIN, 2010, 118). Há assim um desejo, pela parte do materialismo dialéctico, em romper com a visão convencional da cultura, abolindo o seu lado cultual e contemplativo, na medida em que a cultura é agora pertença das massas, mas repugna-Ihe esse lado mercantilista da cultura, que a transforma em objecto de posse. Também a cultura exprime, de acordo com Benjamin, citando o sociólogo Alfred Weber, que procurou uma definição para a cultura nessa época, esses traços fetichistas que são próprios da época, porém, o materialismo histórico sente a sua existência "como superior a tudo o que é vivo e saudável e ela pode destruir" (BENJAMIN, 2010, 118).

Benjamin antecipa aqui teses que desenvolverá no Livro das Passagens e reconhecemos-lhe o tom quando ele afirma que, "para o materialista histórico, a obra cultural do passado não se encontra consumada nem fechada" (ibidem). Deve estar, pelo contrário, aberta à reactualização e ao presente. Essa converte-se na força motriz do próprio trabalho do materialista histórico. $\mathrm{E}$ Eduard Fuchs protagoniza, aos olhos de Benjamin, o historiador da cultura que pensa a história ao arrepio da história continuista, um pioneiro em vários sentidos.

Ao referir-se a Fuchs, mas também ao historiador Franz Mehring (que entrou em contacto com Engels no final da vida deste), Benjamin caracteriza-os como o começo de "uma tradição materialista histórica no âmbito da história das ideias" (BENJAMIN, 1977, 108). No entanto, o trabalho de Mehring tinha poucos pontos de contacto com o de Eduard Fuchs. Aquilo que os distinguia era o facto de Fuchs ser um colecionador, enquanto Mehring era um erudito. $O$ encontro entre ambos foi fundamental para Fuchs tomar conhecimento do pensamento de Engels, que o desperta para uma nova leitura e construção da história. Engels contestava, na história das ideias, o "carácter fechado das várias áreas do saber e da sua produção" (BENJAMIN, 2010, 109).

O que define o percurso singular de Fuchs e o "perfil histórico" da sua obra é o facto de ser colecionador, tendo sido isso aquilo que "ensinou o Professora do Instituto de Arte, Design e Empresa (IADE - Lisboa). Doutora pela Universidade Nova de Lisboa. Portuguesa, residente em Lisboa - Portugal. Email: micantinho@gmail.com 
teórico a aprender muita coisa a que o seu tempo lhe barrava o acesso" (BENJAMIN, 2010, 119). Existe aqui um paralelo bastante interessante com outra figura da história de arte, Aby Warburg, também ele um colecionador. Terá sido, de acordo com Benjamin, "o colecionador que entrou por zonas de fronteira - o retrato deformado, a representação pornográfica - nas quais uma série de chavões da história de arte tradicional mais tarde ou mais cedo têm de fracassar" (Ibidem).

Tendo nascido em 1870, Fuchs tornou-se, na década de 1890, um redactor de uma importante revista que se dedicava à sátira política. A sua experiência como aprendiz de uma tipografia, na década de 80, tinha-o posto em contacto como proletários que eram politicamente activos e acabou por ser atraído para a luta ilegal nas fileiras do socialismo. Em 1887, Fuchs começa a trabalhar para o jornal Münchener Post, onde começou a dedicar-se à sátira política e, mais tarde, à história da sátira e da caricatura. Em pouco tempo tinha a seu cargo a edição de obras sobre os mais importantes artistas plásticos que se dedicavam à sátira e ao erotismo. E cedo compreendeu, pelas suas ideias políticas e orientação materialista dialéctica, "que o seu trabalho se devia dirigir à massa de leitores", como ele próprio o afirma na sua obra Arte Erótica, citado por Walter Benjamin (BENJAMIN, 2010, 115). Foi assim que nasceram, paralelamente ao seu trabalho quotidiano, "os estudos ilustrados sobre o ano revolucionário de 1848 na caricatura" (BENJAMIN , 2010, 112), obra que foi publicada em Munique, em 1898. Como diz Benjamin, "eram as primeiras obras de um historiador ilustradas com material documental, diferentes dos livros de história ilustrados por desenhadores vivos." (Ibidem). Uma estadia de dez meses na prisão, por razões políticas, permitiu-lhe o tempo para desenvolver os estudos sobre a caricatura europeia.

O lado verdadeiramente pioneiro da sua obra foi, sem dúvida, a interpretação da iconografia e do significado da arte de massas e no estudo das técnicas de reprodução, que constituíram a "parte integrante de toda a futura aproximação materialista da obra de arte." (BENJAMIN, 2010, 121). Estes momentos que são aqui referidos têm um ponto comum e que é o facto de remeter "para perspectivas de conhecimento que só podem ser vistas como destrutivas face à forma tradicional de entender a arte." (Ibidem). De facto, em Eduard Fuchs já não se encontram os conceitos de que a burguesia se servia Professora do Instituto de Arte, Design e Empresa (IADE - Lisboa). Doutora pela Universidade Nova de Lisboa. Portuguesa, residente em Lisboa - Portugal. Email: micantinho@gmail.com 
para desenvolver a concepção de arte, como a bela aparência, a harmonia, a unidade do diverso (BENJAMIN, 2010, 120). Arauto da modernidade, o colecionador Fuchs vai apoiar-se na obra de Rodin e de Slevogt, anunciando o advento de "uma nova forma de beleza", insuflada pelo conteúdo intelectual e anímico.

Para a história de arte e para aquele que dela se ocupa e "usa os instrumentos da dialéctica histórica, essas obras integram a sua pré e a sua pós-história - uma pós-história devido à qual também a sua pré-história se torna reconhecível como um processo de transformação permanente." (Ibidem). Há, assim, um desassossego que nasce do desafio que o historiador tem pela frente, no sentido em que precisa de abandonar uma atitude contemplativa relativamente ao seu objecto. Esta concepção da história corresponde ao abandono do historicismo, sendo a actualização do passado no presente, no Agora, o movimento essencial que define a constelação do fenómeno histórico.

Por isso, o materialista histórico terá de renunciar ao elemento épico da história, a essa falsa narrativa que encontra na continuidade o seu princípio. Se o historicista "propõe a imagem eterna do passado; o materialista histórico fá-lo acompanhar de uma experiência única. A substituição do momento épico pelo construtivo revela ser a condição desta experiência" (BENJAMIN, 2010, 110). Assim, pensar a história da cultura desta forma, a partir do presente, "arrancando" o fenómeno histórico à sua sucessão e continuidade, é o que faz interromper o curso dos acontecimentos e permite dar valor àquilo que de outro modo se perderia. E essa experiência histórica permite que se libertem as "gigantescas forças que permanecem presas ao «Era uma vez» do historicismo" (Idem). Ao referir-se a Fuchs e ao seu trabalho, questionamo-nos, por vezes, se Benjamin não estaria a forçar a compreensão de Fuchs, isto é, pergunto-me se o próprio Fuchs se daria conta da tarefa do materialismo histórico como Benjamin o pretende.

Libertar a história deste enleio e restituir aos seus fenómenos culturais um significado histórico, que lhes advém do presente, eis o objectivo do materialista histórico. Esta compreensão, como diz Benjamin, "destrói o contínuo da história" (Idem, 110). Esta compreensão/leitura da história, diz-nos 
ainda Benjamin, "é entendida pelo materialista histórico "como pós-vida" do objecto de compreensão, cujo pulsar se faz sentir até ao presente" (Ibidem). Esta concepção de Eduard Fuchs é verdadeiramente "revolucionária" para Benjamin, que sonhava um novo paradigma epistemológico para a história à luz dessa crítica. No entanto, a visão de Fuchs não é, aos olhos de Benjamin, isenta de crítica, como ele o nota: "Nele coexistem uma ideia antiga, dogmática e ingénua da recepção com a sua forma nova e crítica" (Ibidem). Para Fuchs, "a recepção determinante de uma obra deve ser para nós aquela que ela teve entre os seus contemporâneos" (Ibidem).

Benjamin é aqui muito claro na classificação do trabalho de Fuchs como uma tarefa materialista daquele enquanto historiador. A sua explicação tornase ainda mais pertinente se cruzarmos este texto com os textos sobre a obra de arte na "época da reprodutibilidade técnica", tanto no que respeita às formas de produção da obra, quanto à sua própria recepção. Fuchs, ao lidar com a técnica da reprodução e integrá-la no conceito de arte e de história da arte, teve plena consciência do seu valor político. A técnica da reprodução, aplicada à obra de arte,

(...) emancipa-a, pela primeira vez na história universal, da sua experiência parasitária no ritual. (...) Por exemplo: a partir de uma chapa fotográfica é possível tirar um grande número de cópias; não faz sentido interrogarmo-nos sobre qual será a autêntica. Mas no momento em que o critério de autenticidade deixa de ser aplicável à produção da arte, então também toda a função social da arte se transforma. A sua fundamentação ritualística será substituída por uma outra fundamentação numa outra prática: a política. (BENJAMIN, 2006, 215-216).

É neste sentido que a obra de arte, do ponto de vista da sua produção, se afasta de uma perspectiva mais convencional e fundada numa perspectiva burguesa da arte, assente no seu valor ritual e no critério da autenticidade. $O$ desejo de aproximação das massas à arte, de que nos fala Benjamin no III capítulo do texto "A Obra de Arte na Era da sua Reprodutibilidade Técnica" ( 213) é, em grande parte, responsável pela destruição do seu valor cultual, com o aparecimento da fotografia e da litografia, enquanto técnicas de reprodução. O aqui e o agora da obra, o que constitui a sua autenticidade, dá lugar a uma outra entidade, inédita e que é o resultado da reprodução.

\footnotetext{
${ }^{1}$ Este conceito de pós-vida aproxima-se bastante do conceito de Nachleben de Aby Warburg, de quem Benjamin procurou aproximar-se.

Professora do Instituto de Arte, Design e Empresa (IADE - Lisboa). Doutora pela Universidade Nova de Lisboa. Portuguesa, residente em Lisboa - Portugal. Email: micantinho@gmail.com
} 
Fuchs aborda ainda o conceito de génio, pois, do ponto de vista de uma concepção de arte que tem como seu receptor as massas, a noção de génio precisa de ser revista. Essa marca, a do génio que tem um papel fundamental no nascimento da obra, tanto na sua inspiração, quanto na sua execução, perde a sua conotação convencional (BENJAMIN, 2010, 121). Doravante, a obra de arte emancipa-se do seu criador, torna-se autónoma e independente do seu autor. Podemos acrescentar que esse lado mais espiritual e ideal da obra, mais formal, terá de ceder ao lado material das suas condições de produção.

Neste sentido, na época em que Fuchs lançou os princípios fundamentais da sua obra, o autor vigente e que se encontrava em maior ascensão era Wölfflin. Fuchs tentou articular as suas ideias inovadoras com "um princípio da «arte clássica» de Wölfflin". Na verdade, esse princípio não se restringia a características de conteúdo, mas remetia "para uma evolução do olhar artístico no essencial independente de um ideário e de um ideal de beleza específicos" (BENJAMIN, 2010, 121). Fuchs ancorava-se, assim, num formalismo estético, que procurava conciliar com a sua perspectiva materialista histórica.

Na sua obra Arte Erótica, Fuchs refere-se a esta nova forma de beleza "que, nos seus resultados finais, promete ser infinitamente maior do que a da Antiguidade, pois, se esta era apenas manifestação suprema da forma animal, a nova beleza será preenchida com um grandioso conteúdo intelectual e anímico"2. Deste modo, como conclui Benjamin, analisando as consequências desta ruptura com as teorias da história de arte mais convencionais, a escala de valores que contextualizara e definira os parâmetros da história de arte e determinara a relação com a obra de arte, como no tempo de Goethe ou de Winckelmann, deixou de ter influência em Fuchs, contribuindo para o aparecimento de novos valores na arte ou, pelo menos, para a consideração de valores que não eram tidos em conta no classicismo.

Ainda que Fuchs tenha profetizado o advento de uma nova forma de beleza, a da modernidade, não é, todavia, como nota Benjamin, inteiramente justo dizer que Fuchs destruiu a visão idealista da arte. O que é absolutamente

\footnotetext{
${ }^{2}$ Fuchs, Eduard, Geschichte der Erotischen Kunst, Vol. I, ed. Albert Langen, 1911, p.125.

Professora do Instituto de Arte, Design e Empresa (IADE - Lisboa). Doutora pela Universidade Nova de Lisboa. Portuguesa, residente em Lisboa - Portugal. Email: micantinho@gmail.com
} 
inédito, em Fuchs, é a orientação da sua perspectiva, valorizando outras técnicas, como as da reprodução, aplicadas à caricatura e a sua interpretação da iconografia. E, neste sentido, se o seu trabalho, enquanto historiador, se afastava de uma compreensão burguesa da arte e da sua recepção, ele orientava-se para uma vertente política da arte, isto é, mais voltada para as massas, como por exemplo a litografia e a sátira política, tendo encontrado na obra de Honoré Daumier um objecto privilegiado. Há, assim, um lado completamente inédito, na obra de Fuchs, ao dedicar-se ao estudo e "interpretação da iconografia, no significado da arte de massas, no estudo da arte de massas" (BENJAMIN, 2010, 121), aspectos que são pioneiros e que exprimem a aproximação materialista da obra de arte (Ibidem).

A análise da obra de Daumier, entre outros autores, também possibilitava a Fuchs dedicar-se ao estudo do grotesco, que ele considerava como "a mais elevada potenciação da imaginação sensível" (BENJAMIN, 2010, 124). Nos seus estudos sobre a caricatura, serve-se do exemplo dos povos pré-históricos ou, ainda, do desenho infantil, salientando aspectos que não eram tidos em conta nas teorias da arte convencionais.

$\mathrm{Na}$ verdade, tal como os gregos já haviam compreendido com 0 fenómeno do dionisíaco na arte, "as formas grotescas são também expressão da exuberante saúde de uma época" (BENJAMIN, 2010, 124). Manifestam a força criadora de uma concepção da arte que teve os seus seguidores, não apenas nalguns surrealistas, como também nos expressionistas e, ainda, em autores como Toulouse-Lautrec, que encontraram nele a sua matéria-prima.

Poderíamos, ainda, explorar, como o próprio Benjamin sugeriu (ibidem, 124), mas não desenvolveu aqui, o aspecto doentio e decadente da época que gera o grotesco, revelando na arte esse mal-estar próprio do aparecimento da modernidade como época de alienação e que encontrou em expressões artísticas como o grotesco e expressionismo, uma forma de libertação e de apresentação desses fenómenos próprios do seu tempo.

São sem dúvida estes os apectos mais interessantes da obra de Fuchs, não apenas do ponto de vista benjaminiano, como do ponto de vista do seu contributo para a história de arte e para os estudos sobre iconografia no século XX. Se a visão de Fuchs rompe com a visão clássica da história de arte, ela só pode ser entendida como visão do materialista histórico, isto é, a do historiador Professora do Instituto de Arte, Design e Empresa (IADE - Lisboa). Doutora pela Universidade Nova de Lisboa. Portuguesa, residente em Lisboa - Portugal. Email: micantinho@gmail.com 
de arte que interpreta a história, ao arrepio da sua própria época e dos valores burgueses que a norteavam. Se esses valores, como por exemplo o grotesco, tinham estado presentes na história de arte, haviam sido totalmente ignorados por não "caberem" nos cânones da história de arte convencional e, por isso, haviam sido relegados para um segundo plano. Na medida em que a história de arte classicista apenas valorizava uma concepção do belo ideal e uma determinada visão da arte, ideal e harmoniosa, estes novos aspectos que emergem na arte do século XIX e XX, escapam a uma concepção classicista e começam agora a ser valorizados pelo historiador de arte que é, neste caso, Eduard Fuchs. Trata-se assim, para repetir uma ideia que é aqui desenvolvida, de "escovar a contrapelo uma determinada visão da história da cultura" que apenas concedia lugar a uma visão da história da arte da cultura, isto é, arrancando esse fenómeno ao contínuo da história e obrigando-o a significar.

É o que se passa aqui "com a apresentação do grotesco e da caricatura erótica" (BENJAMIN, 2010, 125). É nas alturas de decadência que «"a coisa suja" e a "brejeirice picante", em épocas de ascensão é "expressão de prazer transbordante e pujança"» (Ibidem, 125). Fuchs compreende nessas manifestações culturais, como a sátira e o erotismo a expressão de vitalidade da sua época, que já não se reconhece nos ideais estéticos do classicismo. Uma época que elegeu agora como novas formas de arte a litografia e a fotografia, que repudia o elitismo dos salões de arte e a contemplação como modo de recepção da arte. São, assim, dois modos completamente distintos de olhar para a arte e é interessante relembrar o texto de Baudelaire, em que o poeta critica ferozmente as primeiras exposições de fotografia, não a considerando como arte, mas como "imitação da realidade". Por detrás do olhar de Baudelaire perfila-se toda uma tradição clássica da história de arte e da crítica de arte, que ainda não possui instrumentos críticos de interpretação das novas formas emergentes e que, por isso, ainda se ancora no ideal da arte como contemplação.

Quando Fuchs afirma de forma optimista que "A arte de hoje trouxe-nos a concretização de centenas de sonhos que, nos mais diversos sentidos, vão muito além do que o Renascimento alcançou e a arte do futuro terá de ser necessariamente superior" (BENJAMIN, 2010, 129), exprime essa confiança e abertura que fez dele um materialista histórico. Não só valoriza os novos Professora do Instituto de Arte, Design e Empresa (IADE - Lisboa). Doutora pela Universidade Nova de Lisboa. Portuguesa, residente em Lisboa - Portugal. Email: micantinho@gmail.com 
fenómenos artísticos como os reconhece como "imagens do passado" que se actualizam no presente, pois esses valores sempre estiveram presentes na arte, embora se tivessem mantido relegados para um plano inferior. $E$ a história de arte classicista ignorava-as e valorizava apenas os valores que encarnavam no seu ideal. Trata-se, assim, de resgatar esses valores que sempre estiveram presentes na arte e que as formas de arte que emergiram com as técnicas de reprodução vieram dar relevo.

Trata-se de um modo de pensar no qual Benjamin reconhece uma afinidade própria. Mais do que uma crítica a uma determinada concepção da arte que se revelava anacrónica, Fuchs veio impulsionar as novas investigações sobre a arte, obrigando à inflexão do olhar para formas de arte que escapavam à análise da história. A interioridade burguesa cede o lugar à litografia, ao erotismo e à sátira e nada escapa ao olhar das massas, que vê na caricatura de Honoré Daumier uma arte tão digna quanto a pintura ou a escultura.

Eis-nos chegados a um ponto que nos parece decisivo. A visão da cultura de Fuchs é atravessada por uma crítica ao moralismo burguês, assente na repressão da sexualidade. A sua defesa da força vital como fonte de criatividade é dos aspectos mais interessantes da sua obra, indo ao ponto de dizer:

(...) o prazer da orgia é uma das mais valiosas tendências da cultura...Temos de ter presente que a orgia é uma das características que nos distinguem dos animais, que, ao contrário dos humanos, não conhecem a orgia... O animal ignora a mais suculenta das refeições e a mais cristalina das fontes se estiver saciado de fome e sede, e o seu apetite sexual quase sempre se restringe a certos períodos curtos do ano. O ser humano é muito diferente, sobretudo o ser humano criativo, que não conhece limites" (BENJAMIN, 2010, 137).

$\mathrm{Na}$ verdade, as suas ideias, defendendo a ideia de que o erotismo é a mais viva fonte da criatividade humana, põe em causa as normas tradicionais. É interessante notar como ele já antecipa a psicanálise de Freud. Tendo aceite com entusiasmo a teoria das origens eróticas do impulso criativo, continuou, no entanto, muito preso à ideia de uma sensualidade biologicamente determinada (BENJAMIN, 2010, 138).

Foi com a análise da obra de Honoré Daumier que Fuchs "se tornou um pensador dialéctico" (Ibidem, 139), nas palavras de Benjamin, se tomarmos 
este conceito como portador de vivas contradições que se apresentam simbólica e imageticamente. Se, por um lado, apreendeu "o elemento maternal" na arte de Daumier, por outro também se familiarizou com o outro pólo, masculino e mais polémico. Aquilo que atraiu sobremaneira Fuchs foi "o momento agónico desta obra" (Ibidem, 140).

Com efeito, foi Fuchs quem reuniu os primeiros álbuns de Daumier (e de Gavarni) na Alemanha. Não apenas enquanto historiador de arte, mas também enquanto colecionador, ele teve um papel fundamental na cultura francesa do século XIX. De Fuchs dizia Edouard Drummont: "C'est le Monsieur qui mange tout Paris", aludindo à exuberância megalómana da sua colecção. Essa dimensão de colecionador atraiu sobremaneira o olhar de Benjamin. Nunca é demais lembrarmo-nos da importância que o próprio deu ao tema e à sua análise, nomeadamente na sua obra O Livro das Passagens, tendo consagrado todo um capítulo a este tema, nomeadamente a Letra H (BENJAMIN , 1982).

Porém, Fuchs não foi um colecionador qualquer, tendo sido, nas próprias palavras de Walter Benjamin, "um pioneiro: fundador de um arquivo, único da sua espécie, que documenta a história da caricatura, da arte erótica e dos quadros de costumes" (BENJAMIN , 2010, 108).. Comparando-o a uma figura de Balzac, dizendo de Fuchs que ele é "tipicamente balzaquiano, é uma figura de Balzac que ultrapassou o seu próprio criador." (Ibidem, 131). Se o colecionador "dispõe, na sua paixão, de uma varinha de vedor que o transforma em descobridor de novas fontes" (BENJAMIN, 2010, 141), tal aplica-se a Fuchs, de acordo com Benjamin, pois ele fazia parte de uma série de grandes colecionadores que se dedicava com paixão a uma ideia, isto é, procurando

\footnotetext{
restituir à obra de arte a sua existência na sociedade, da qual havia sido de tal modo segregada que o lugar onde ele a foi encontrar era o de um mercado em que ela, igualmente afastada dos seus produtores e daqueles que a poderiam compreender, sobrevivia reduzida à sua condição de mercadoria (BENJAMIN, 2010, 142).
}

Se o fetiche do mercado da arte é o nome do mestre, então, diz Benjamin, "Do ponto de vista histórico, talvez o maior mérito de Fuchs tenha sido o de ter encetado a libertação da história da arte deste fetiche do nome do mestre." (Ibidem, 142-143). Neste sentido, Fuchs retira-lhe esse fetiche e liberta-o dele, para o integrar numa nova forma de recepção da arte, que é a 
arte de massas. Ele insere-se numa série de grandes colecionadores cuja ideia fundamental era de "restituir à obra de arte a existência na sociedade" (BENJAMIN, 2010, 142), subtraindo-a à sua "condição de mercadoria". Explicao com clareza, no seu livro sobre a Escultura Tang, ao falar do anonimato das oferendas funerárias. Não existe nessas esculturas um caso de criação individual e Fuchs lê nela o modo "como o mundo e as coisas eram vistas pela totalidade da população" (BENJAMIN, 2010, 143).

Ele descobre assim na arte de massas e na reprodutibilidade das obras de arte uma verdadeira libertação da arte, das suas convenções e do idealismo que a constrangia. Consciente dos efeitos que a reprodução técnica operava sobre a arte e da força libertadora que esta conferia à própria arte, Fuchs não fez outra coisa senão abrir novos caminhos, explorando um novo modo de olhar a história da cultura, não a partir de um passado fixo, mas antes de um presente que salvava as imagens do passado. Enquanto colecionador ele "liberta as coisas da subserviência de serem úteis" (BENJAMIN, 1982, [H 3a, 1]), ou seja, do seu lado de mercadoria, para as transformar em objectos de saber durável. Ao apropriar-se desse objecto, o que o coleccionador pretende é salvá-lo nessa nova ordem de conhecimento, inscrevê-lo numa nova ordem de sentido. É, sem dúvida, em Fuchs que Benjamin se inspira, para escrever o capítulo do Livro das Passagens sobre o colecionador, reflectindo sobre o seu olhar de colecionador.

O que fazem, então, os historiadores quando estudam arte? Devem limitar-se a reproduzir os modelos vigentes e aplicá-los ao seu objecto? Quase sempre eles fazem-no, seguindo a tradição e inscrevendo-se na continuidade dessa tradição. Retomando o conceito de paradigma, tal como ele é definido na obra de Thomas S. Kuhn, A Estrutura das Revoluções Científicas, é um procedimento natural que se vá integrando os fenómenos no quadro de um paradigma vigente, estabelecendo a possibilidade da própria crítica e a legitimidade da produção da história. Também o critério é válido para a história de arte. Durante muito tempo, a história de arte procurou integrar esses fenómenos no quadro conceptual do classicismo histórico, norteado por conceitos que permitiam reconhecer a obra de arte. Todavia, no século XIX, a humanidade sofreu um desenvolvimento vertiginoso da técnica, que afectou todas as suas formas de produção, onde as formas de arte emergentes já não Professora do Instituto de Arte, Design e Empresa (IADE - Lisboa). Doutora pela Universidade Nova de Lisboa. Portuguesa, residente em Lisboa - Portugal. Email: micantinho@gmail.com 
eram reconhecíveis à luz do classicismo. O mérito de Fuchs foi o de ter compreendido as grandes mudanças que se operavam, tentando compreender a Arte à luz de um novo paradigma: o materialismo histórico.

\section{REFERÊNCIAS}

BENJAMIN, W. (1972). Gesammelte Schriften I. Frankfurt am Main: Suhrkamp Verlag.

Suhrkamp Verlag.

(1972). Gesammelte Schriften IV. Frankfurt am Main: . (1977). "Eduard Fuchs, der Sammler und der Historiker." In W. BENJAMIN, Gesammelte Schriften, II, 2. Frankfurt am Main: Suhrkamp Verlag.

Suhrkamp Verlag.

(1982). Gesammelte Schriften V. Frankfurt am Main: . (1993). Briefe II. Frankfurt am Main: Suhrkamp Verlag.

Suhrkamp Verlag.

(1998). Gesammelte Briefe (Vol. IV). Frankfurt am Main: . (1999). Gesammelte Briefe (Vol. V). Frankfurt am Main: Suhrkamp Verlag.

. (2000). Gesammelte Briefe (Vol. VI). Frankfurt am Main: Suhrkamp Verlag.

. (2006). A Modernidade. Lisboa: Assírio \& Alvim.

. (2010). "Eduard Fuchs, Coleccionador e Historiador." In W. BENJAMIN, O Anjo da História (pp. 107-144). Lisboa: Assírio \& Alvim.

Assírio \& Alvim. . (2010). O Anjo da História. (J. Barrento, Trans.) Lisboa:

CANTINHO, M. J. (2011, Março). Walter Benjamin, revolução e messianismo: a história secreta. Retrieved from academia.edu: https://www.academia.edu/1133869/Walter_Benjamin_Revolu\%C3\%A7\%C3\% A3o_e_Messianismo_a_Hist\%C3\%B3ria_Secreta

LAVELLE, P. (2008). Religion et Histoire. Paris : Éditions du Cerf.

Professora do Instituto de Arte, Design e Empresa (IADE - Lisboa). Doutora pela Universidade Nova de Lisboa. Portuguesa, residente em Lisboa - Portugal. Email: micantinho@gmail.com 
PULLIERO, M. (2005). Walter Benjamin, le désir d'authenticité. Paris: Bayard. 